\title{
Teaching and Practice of Digital Image Processing Curriculum Based on Engineering Application
}

\author{
Hong Jin Zhu ${ }^{1, a}$, Jie Zhang ${ }^{1, b}$, Xiao Rong Zhao ${ }^{1, c}$ and Hong Hui Fan ${ }^{1, d^{*}}$ \\ ${ }^{1}$ School of Computer Engineering, Jiangsu University of Technology, Changzhou 213001, China \\ azhuhongjin@jsut.edu.cn, bzhangjie@jsut.edu.cn, czhaoxr432698@gmail.com, \\ fanhonghui@jsut.edu.cn
}

Keywords: Digital image processing; Professional education; Teaching reform and practice; Engineering application; Project driven

\begin{abstract}
Digital image processing technology is widely used in the further application of computer graphics. Based on analysis of the characteristics of digital image processing course, instructional objectives, the project based learning theory and method was applied to the instructional reform and practice in experimental of digital image processing. Based on the necessity of digital image processing in teaching reform, a practical teaching method based on engineering application, which is including four parts such as designing project components, organizing teaching continents, practicing after class and evaluating students was proposed. On the basis of the target of teaching reform, set of teaching content, arrangement of the class hour and teaching method, the research of teaching practice has been done, and good effects in teaching of engineering application have been achieved. Educating contents are organized by considering project components and teaching syllabus. Different degree of difficulty objects can be chosen by students to satisfy with different students.
\end{abstract}

\section{Introduction}

Digital image processing is the process of processing digital images with various techniques such as restoration, denoising, segmentation, edge detection etc.. Image processing technology has been implemented in aerospace engineering, medical, industrial detection, security monitoring, and culture has been widely applied in every areas. It has become a compelling, and has the prospect broad. Image processing technology is computer science and technology professional course of the compulsory courses, with strong professional and comprehensive, through the teaching of this curriculum can let student to study the graphic image processing theory knowledge and mastery of the technology and image processing application [1, 2]. However, we found the process in teaching, comprehensive knowledge is broader, in addition to asking students to grasp the basic concepts of image processing, beyond the basic theory, basic knowledge of the typical methods, but also need to have some practical programming skills, be able to take advantage of computer programming graphic image information processing applications [3]. Teaching digital image processing is a challenge for teachers who are handling students of all learning styles. Digital image processing concepts can easily be understood if they are taught using visual, experimental and interactive methods [4].

Digital image processing curriculum for students in programming and have some basic knowledge of mathematics require high starting point, it is difficult, and it is based on the theory of many engineering applications, it is taught in the curriculum process to stimulate students' creative thinking, to mobilize student learning enthusiasm and abstract content becomes vivid and specific, improve students' practical ability [5, 6]. With the rapid development of image processing technology, the teaching content of the course is also constantly updated, teaching methods and means also put forward higher requirements, so teachers need to continue to reform the teaching process, and actively carry out image processing technology teaching content practice and exploration [7]. European and American universities to teach courses on digital image processing are basically based on the practical application of theoretical knowledge to drive students with specific applications, so that students with interest and self-study problems. Professor of European and American universities at the same time 
have their own research projects, often based on a fundamental part of research projects to the students to explain the specific application of theoretical knowledge to enable students to experience the fun of the application of knowledge, and thus further into teaching high level of knowledge [8, 9].

However, some colleges and universities in teaching, the teacher just taught step by step in accordance with the outline, but most colleges and universities do not require the outline procedures to achieve and application part, so most teachers will only explain the theory of realization of the program [10]. The students are just step by step learning of theoretical knowledge, there is not much use, with the deepening of the curriculum, students lose interest in the program, even serious student, but also in a passive learning state. Therefore, the current digital image processing methods on the innovative teaching practice ability of students through project-based education reform, to further stimulate interest in learning to effectively improve the students' practical and innovative ability, and cultivating innovative practice ability in the teaching process.

\section{Teaching Methods}

With the rapid development of digital image processing technology and the social demand for digital product development, the course of the teaching content should be the following aspects (see Fig .1).

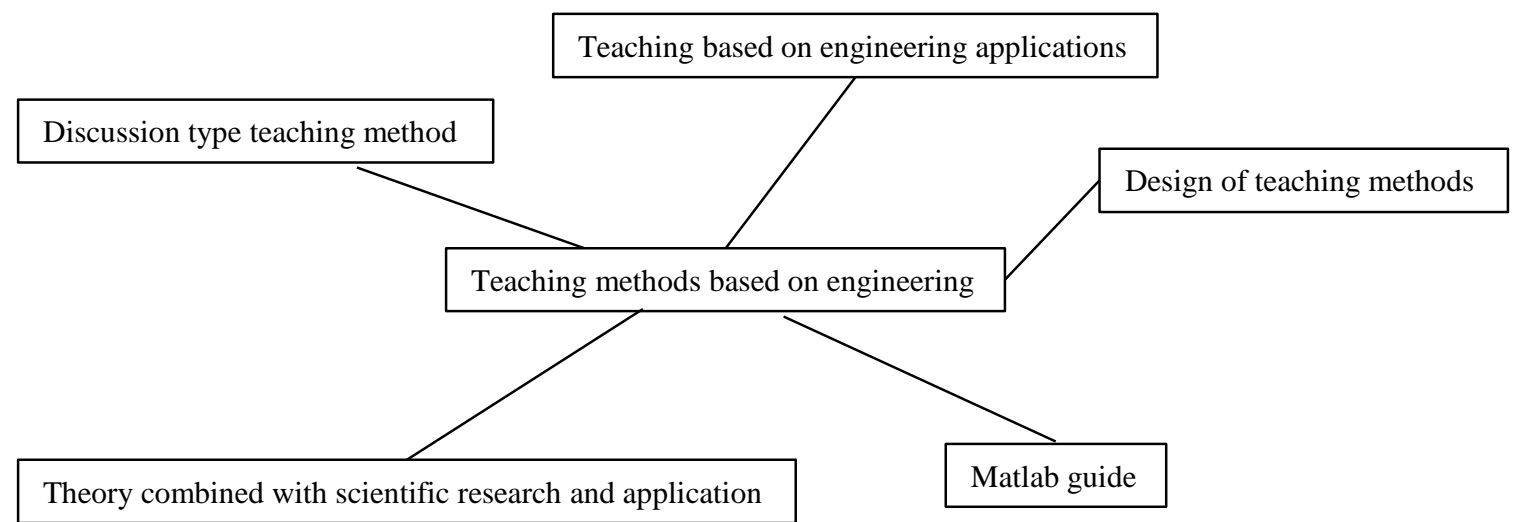

Figure. 1 Teaching methods based on engineering

Specific content as follows:

- Discussion type teaching method. Discussion type teaching method should belong to the category of research-oriented teaching mode. In recent years, research-based teaching and research learning become widely touted the teaching and learning methods, and conducted a large number of empirical studies.

- Teaching based on engineering applications. Practical projects related to image processing part to enter into the teaching, and the combination of classroom content, linked with the theoretical knowledge to enable students to learn the theoretical basis of knowledge, understanding of the direction of cutting-edge technology and applications for future learning and has an important role in guiding the work, to apply their knowledge to achieve real, while the formation of the project led to teaching, teaching to promote a virtuous cycle of the project.

- Design of teaching methods. With teacher guidance, students' learning, in-class discussion, the teacher to answer questions arranged in the form of teaching activities, and cooperate with the verification and design experiments to expand students' learning and innovation space.

- Theory combined with scientific research and application. With the application of scientific research project solves the problems of the professional course content abstract. Based on image processing applied in teaching of stimulate students interest in learning to improve students' understanding of professional knowledge and perceptual knowledge.

- Matlab guide. Matlab is a high-performance engineering language for numerical calculation and visualization graphics tools, it will be numerical analysis, matrix computation, graphics, image processing, signal processing and simulation integrated into an organic whole. Fully 
using the Matlab image processing toolbox, can make the abstract concept of embodiment and convenient processing results, make the teacher teaching and student learning through the establishment of theoretical understanding on the interactive instance.

In order to get better teaching effect, the five kinds of teaching methods should be comprehensive use in teaching process,.

\section{Teaching Content Reform}

When teaching Image processing knowledge for students as popular as possible to describe the principle of image processing algorithms and implementation method, to ensure that the students can understand and master, and use case narrative, concrete face detection research content into the teaching of digital image processing. As showed in Fig. 2, that the specific process of the face detection with digital image processing in the process of teaching.

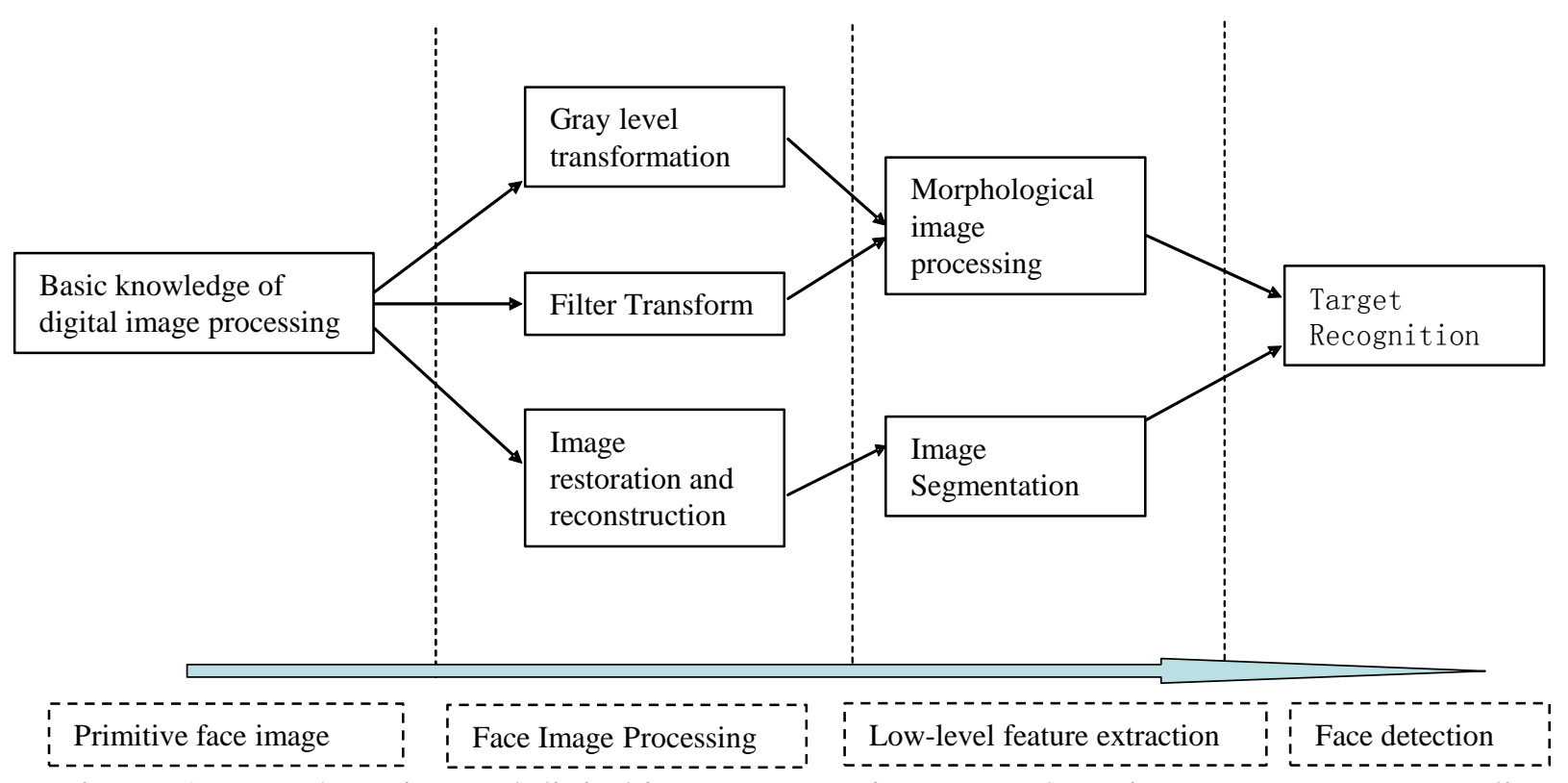

Figure. 2 Face detection and digital image processing research project courses corresponding cases

The concrete teaching measures:

- On the choice of teaching material and teaching content arrangement, according to the actual needs of students and teaching in a selection of teaching material and teaching content of reasonable arrangement.

- On the choice of teaching content should apply the principle of fewer but better course content for the proper selection and update. In a special form to introduce students to the latest, frontier discipline knowledge.

- The application of visualization teaching means teaching, in view of the digital image of the image information is rich, the effect of before and after the image processing using Matlab live demonstration.

- Using programming skills for all of image information processing, such as image enhancement, image segmentation, image analysis, etc.

- Selection of the experimental teaching content, emphasizes the combination of theoretical knowledge and practical ability, the image gray level enhancement, image compression, image thresholding segmentation and pseudo color processing as the main experiment content, further enhance the initiative and enthusiasm of the students' to complete the task, effectively improve the students' ability of programming practice. 
- Develop additional classroom activities. To effectively develop the students' practical ability, rapidly improve the students' theory of cognitive level and ability to solve practical problems, in the beginning of class the students group each group is given a practical term project. With sufficient time to collect data and imitation learning, improve the students' study enthusiasm. Will combine classroom experiment tasks and term project, help students find learning content links, promote grasp and flexible application of knowledge.

Based on the content of teaching reform, we can get good teaching effect. Both in theory and practice, this teaching content reform can promote students' learning effect.

\section{Summary}

Digital image processing teaching reform project, based on the teaching content, experimental system and assessment methods and ways of improvement, targeted teaching based on engineering, through teaching visualization instantiation, can improve the learning enthusiasm of students, enhance the teaching effect. In accordance with the requirements of undergraduate education plan and strengthen the practice teaching of the new characteristics of digital image processing course will further the reform of the teaching contents and mode to meet the current developing trend of computer science and the social demand for IT.

Systemic and engineering in teaching content, interactive discussion and exploration in the aspect of teaching methods for students learning together, can make the students master the basic knowledge of digital image processing, advanced methods and the latest technology, have strong ability of knowledge development, for subsequent combining professional direction to lay a solid foundation for further study. Careful study of computer professional undergraduate course applied innovative talents training approaches and methods, from the perspective of teaching reform to promote the quality of teaching enhancement, will have important significance.

\section{Acknowledgements}

This work was supported by teaching reform project of Jiangsu University of Technology (JG13012、 JG13014、11610311415).

\section{References}

[1] E. Jebamalar Leavline and D. Asir Antony Gnana Singh, C. Zhang: American Journal of signal Processing, Vol. 4 (2014) No. 1, p. 7-15.

[2] A. G. D. Asir, L. E. Jebamalar: International Journal of Education and Learning, Vol. 2 (2013) No. 1, p. 25-34.

[3] S. Ahmad and S. M. Muddassir: First International Conference on Modern Communication and Computing Technologies (Nawabshah, Pakistan, February26-28, 2014). p. 26-28.

[4] S. Khorram, S. Nelson, H. Cakir, C. V. D. Wiele: Digital Image Processing: Post-processing and Data Integration (Springer, America, 2013).

[5] M. Sonka, V. Hlavac and R. Boyle: Image processing, analysis, and machine vision (Cengage Learning, America 2014).

[6] L. Lin: Journal of Fujian Teachers University (Natural Science), Vol. 3 (2011) No. 1, p. 14-17 (In Chinese).

[7] C. Solomon C and T. Breckon: Fundamentals of Digital Image Processing: A practical approach with examples in Matlab (John Wiley and Sons, America 2011).

[8] P, Li and D. J. Lilja: 2011 IEEE 29th International Conference on Computer Design (Amherst, America, Octomber 9-12, 2011). p. 154-161. 
[9] J. H. Wang and Y. X. Hao: China Academic Journal Electronic Publishing House, Vol. 21 (2011) No. 1, p. 46-51.

[10]P. Balakrishnan, S. Muruganand and K. Sriram: International Journal of Computer Science Issues, Vol. 9 (2012) No.1, p.294-298. 